\title{
A enfermagem na redução de acidente com material perfurocortante: um olhar para saúde do trabalhador
}

\section{Nursing in the reduction of accidents with sharps: a look at workers' health \\ Enfermería en la reducción de accidentes con objetos punzantes: una mirada a la salud de los traba- jadores}

\section{Mayara Cristina Maranhão Ramos ${ }^{1 *}$, Eliara Adelino da Silva ${ }^{2}$, Alessandra da Silva Souza ${ }^{3}$, Carolina de Lourdes Julião Vieira ${ }^{4}$, Jannaína Sther Leite Godinho Silva ${ }^{5}$, Lília Marques Simões Rodrigues ${ }^{6}$}

Como citar esse artigo. Ramos, MCM; da Silva, EA; Souza, AS; Vieira, CLJ; Silva, JSLG; Rodrigues, LMS. A enfermagem na redução de acidente com material perfurocortante: um olhar para saúde do trabalhador. Revista Pró-UniverSUS. 2021 Jul./Dez.; 12 (2) SUPLEMENTO: 79 - 84

\section{Resumo}

Este estudo tem como objetivo identificar as falhas ocasionadas durante a assistência de enfermagem devido a falta de atenção laboral e os motivos da não adesão dos equipamentos de proteção individual com enfoque na redução de acidente com material perfuro cortante. Trata-se de uma revisão bibliográfica de literatura, realizada no banco de dados online BIREME, SciELO e Lilacs encontrados entre os anos de 2015 à 2019. Os resultados evidenciaram, que os profissionais de enfermagem estão mais propícios aos riscos de acidentes laborais pela vulnerabilidade ao estar diretamente com o paciente e até pelas altas cargas de trabalho, o descarte inapropriado dos materiais incluindo a falta de atenção e o risco do acidente com perfurocortante que constitui um grande problema na ocorrência do Vírus da Imunodeficiencia Humana (HIV), Hepatite B (HBV), Hepatite C (HCV). É imprescindível a fiscalização do cumprimento das normas de biossegurança para que os acidentes de trabalho não sejam subnotificados a qual podem desencadear injurias o que inviabiliza no acompanhamento sorológico.

Palavras-chave: Acidente de trabalho; Enfermagem; Perfurocortantes; Saúde do trabalhador.

\begin{abstract}
This study aims to identify the failures caused during nursing care due to lack of work attention and the reasons for nonadherence to personal protective equipment with a focus on reducing accidents with sharp materials. This is a literature review, carried out in the online database BIREME, SciELO and Lilacs found between the years 2015 to 2019. The results showed that nursing professionals are more prone to the risks of occupational accidents due to vulnerability to work. being directly with the patient and even due to the high workloads, the inappropriate disposal of materials including the lack of attention and the risk of a sharp needle accident that constitutes a major problem in the occurrence of the Human Immunodeficiency Virus (HIV), Hepatitis B (HBV), Hepatitis C (HCV). It is essential to inspect compliance with biosafety rules so that accidents at work are not underreported, which can trigger injuries, which makes serological monitoring unfeasible.
\end{abstract}

Keywords: Work accident; Nursing; Sharps; Worker's health.

\section{Resumen}

Este estudio tiene como objetivo identificar las fallas ocasionadas durante el cuidado de enfermería por falta de atención laboral y los motivos de la no adherencia a los equipos de protección personal con un enfoque en la reducción de accidentes con materiales cortantes. Se trata de una revisión de la literatura, realizada en la base de datos en línea BIREME, SciELO y Lilacs encontradas entre los años 2015 a 2019. Los resultados mostraron que los profesionales de enfermería son más propensos a los riesgos de accidentes laborales por vulnerabilidad al trabajo. estar directamente con el paciente e incluso debido a las altas cargas de trabajo, la disposición inadecuada de materiales incluyendo la falta de atención y el riesgo de un accidente con objetos punzantes que es un problema importante en la ocurrencia del Virus de Inmunodeficiencia Humana (VIH), Hepatitis B (VHB) ), Hepatitis C (VHC). Es fundamental fiscalizar el cumplimiento de las normas de bioseguridad para que los accidentes de trabajo no sean infrarreportados, que pueden desencadenar lesiones, lo que hace inviable el seguimiento serológico.

Palabras clave: Accidente de Trabajo; Enfermería; Objetos Punzantes; Salud del Trabajador.

Afiliação dos autores:

${ }^{1 *}$ Acadêmica do Curso de Enfermagem, Universidade de Vassouras. RJ, Brasil. E-mail: mmayaramaranhao@gmail.com ORCID: https://orcid.org/0000-0003-2479-0847 ${ }^{2}$ Enfermeira. Terapeuta Holística, Mestre. Docente do Curso de Enfermagem, Universidade de Vassouras. RJ, Brasil. Email: eliaraadelinos@uol.com.br ORCID: https://orcid. org/0000-0003-4387-6662

${ }^{3}$ Mestre. Docente do Curso de Enfermagem, Universidade de Vassouras. RJ, Brasil. E-mail: alesouza22@yahoo.com.br ORCID: https://orcid.org/0000-0002-9009-9774 ${ }^{4}$ Doutora. Docente do Curso de Enfermagem, Universidade de Vassouras. RJ, Brasil. E-mail: caroljuliaovieira@gmail.com ORCID: http://orcid.org/0000-0002-5785-5988 ${ }_{5}^{5}$ Mestre. Docente do Curso de Enfermagem, Universidade de Vassouras. RJ, Brasil. E-mail: jjasther@gmail.com ORCID: https://orcid.org/0000-0002-8308-2093

${ }^{6}$ Mestre. Coordenadora e Docente do Curso de Enfermagem, Universidade de Vassouras. RJ, Brasil. E-mail: liliasrodrigues21@gmail.com ORCID: https://orcid.org/0000-00032979-6316. 


\section{Introdução}

A enfermagem é uma ciência humana com o foco da prática de cuidar dos seres humanos, e o enfermeiro do trabalho é o profissional que tem o nível de pósgraduação, além de prestar assistência atua em hospitais, empresas voltadas para o ramo de saúde do trabalhador, com o objetivo de promover saúde e prevenir acidentes de trabalho. ${ }^{1}$

O profissional especialista desempenha papéis fundamentais, como atividades relacionadas à higiene ocupacional, segurança e medicina, além de compreender a saúde como a qualidade de vida dos trabalhadores de enfermagem. ${ }^{2}$

Para que o cuidado seja efetivo/eficaz, temos que cuidar da nossa saúde, assim poderemos prestar cuidados aos outros, e para promover educação continuada, temos que praticar no nosso dia dia, somos exemplos a serem seguidos, portanto é de extrema importância utilizar os EPIs e descartar os materiais no local adequado para que possamos influênciar os profissionais com nossos atos e, assim, trazer resoluções de problemas.

O Enfermeiro do trabalho tem como objetivo levar uma prática segura ao ambiente de trabalho, para promoção e prevenção de acidentes, diante das normas regulamentadoras, pois muitos trabalhadores são expostos a diversos riscos, além das falhas envolvidas, sejam elas o manuseio incorreto do produto, ou o descarte inapropriado. ${ }^{2}$

Portanto, o papel do profissional de enfermagem vai além de estimular a redução de acidentes ocasionados no local de trabalho e fomentar a importância do uso dos EPIs e o descarte correto dos materiais. ${ }^{3}$ Assim, a atribuição deste profissional constitui na conscientização de erros advindos da equipe de enfermagem e encorajar estes profissionais, pois "alguns" sentem medo que ao se perfurarem, não relatam o acidente por medo de perderem seu trabalho.

No marco da evolução, vale ressaltar a teoria ambientalista desenvolvida pela pioneira da enfermagem, que tem como objetivo focar no ambiente e afirma que a ausência destes fatores como a iluminação, limpeza e ar puro nenhum local seria saudável. ${ }^{4}$

Nightingale descreve ambiente como sendo o local no qual se encontra o doente e/ou os familiares, compreendendo as instituições de saúde e o domicílio, e considerando seus componentes físico, social e psicológico, os quais precisam ser entendidos como inter-relacionados. ${ }^{5}$

Nesta situação, o ambiente de trabalho está relacionado não somente ao doente e sim ao profissional que executa a atividade laboral que dá ênfase aos Determinantes Sociais da Saúde, as condições de vida, emprego, desemprego e está na posição centralizada, para dar ênfase sobre a importância desse determinante aliado a outros subtipos. ${ }^{6}$

Neste sentido, pensando que o local de trabalho repercute diretamente na saúde do trabalhador, podemos relacioná-lo também com da teoria ambientalista de Florence Nightingale, tomando também por empréstimo o que o Ministério da Saúde define em seu caderno de atenção básica $n^{\circ} 41$, quando diz que o trabalho é um dos determinantes da saúde e do bem-estar do trabalhador e de sua família. ${ }^{7}$ Portanto, focar no contexto do ambiente laboral, além de gerar renda, mantém as condições materiais de vida, e permite a inclusão social de quem trabalha, a fim de favorecer educação, sustento, e qualquer quebra ou ruptura existente poderá repercutir em situações danosas para a saúde do trabalhador.

A teoria ambientalista de Florence Nightingale, juntamente com os determinantes da saúde, tem uma ligação pois se garantirmos um ambiente apropriado irá permitir assim o bem estar do trabalhador, promovendo saúde e bem estar e, por fim, a renda, a qual o trabalhador poderá pagar suas contas, e garantir a alimentação. Contudo, irá firmar o que está descrito no caderno 41 sobre os determinantes. ${ }^{4,5,6}$

O trabalho tem um efeito promotor de saúde, pois "alguns trabalhadores" se sentem agraciados de ter seu pão de cada dia, e que todo esforço gerado, ao final do mês, pode-se dizer que valeu a pena, mas, em contrapartida, pode causar mal-estar, sofrimento, adoecimento, pois existem as altas cargas de trabalho, sejam elas por dobrarem o plantão ou até mesmo pelo salário da classe. Estes problemas estão relacionados a diversos riscos que podem trazer danos futuros, como psicossociais, ruídos, químicos, físicos, mecânicos e biológicos. $^{7}$

A saúde do trabalhador, segundo o Ministério da Saúde, define que é a área da Saúde Pública que tem como objetivo estudar e intervir sobre as relações produção consumo e o processo saúde-doença das pessoas e, em particular, dos(as) trabalhadores(as). ${ }^{7,8}$

Segundo a lei 8.213/91, como dispõe o art. 19, acidente de trabalho é quando ocorre pelo exercício laboral provocado por qualquer lesão corporal ou perturbação funcional que lhe cause algum dano seja ele a perda ou redução permanente ou temporária ou morte. ${ }^{9}$

Os fatores para o acontecimento de acidentes de trabalho incluem as altas cargas de trabalho a que estes trabalhadores estão expostos que, por fim, adoecem, e os principais riscos a que os trabalhadores estão expostos são de origem: biológica, física, química, mecânica, fisiológica e psíquica. ${ }^{10,11}$

Para este estudo, pode-se citar somente de origem biológica e mecânica relacionados aos perfurocortantes, além de ressaltar a importância desse grupo por ser potencializado pelas cargas biológicas e em contaminar trabalhadores com vírus da hepatite B e C e o HIV. ${ }^{11,12}$

$\mathrm{O}$ estresse advindo de uma das causas mais 
referidas pelos trabalhadores de enfermagem, pelas altas cargas de trabalho, jornada, ambientes hostis, o que posteriormente pode levar a um quadro de depressão, angústia, falta de interesse, pois a carga de trabalho influencia na assistência ao paciente e sua exposição a essas cargas geram vários problemas. ${ }^{12}$

Os trabalhadores de enfermagem estão expostos durante a prática laboral juntamente com o ambiente no qual ele está inserido, podendo ser a iluminação, limpeza e, por fim, ambiente hostil, que contribuirá para o estresse. E nesta rotina desperta a injúria aos trabalhadores que estão expostos a inúmeros riscos ocasionados por diversas cargas de trabalho, sejam elas de origem psíquica, biológica, química, física a qual elas levam um dano, as contaminações. ${ }^{13,14}$

Segundo a "teoria dos dominós" os atos e as condições inseguras evidenciam que o acidente é uma cadeia de varios fatores que influenciam na sequencia destes dominos e por fim a lesão. ${ }^{15,16}$ Levando em consideração os acidentes laborais, a cascata de efeitos inicia-se em altas cargas trabalhistas, desinteresse, a falta da atenção nas práticas, levando ao descarte inapropriado e por fim se acidentam ocorrendo a lesão, a infecção pelo HIV, Hepatite B e Hepatite C.

Para que haja proteção dos trabalhadores, existem normas de biossegurança que estabelecem medidas para segurança nos serviços de saúde, com o objetivo de prevenir acidentes e o adoecimento, mas para que seja efetivo é de suma importância a fiscalização do cumprimento das mesmas. ${ }^{17}$

A partir do tema pesquisado, traçamos os seguinte objetivo: identificar falhas ocasionadas durante a prática laboral, que incluem a falta de atenção e os motivos da não utilização dos equipamentos de proteção individual.

\section{Metodologia}

O presente estudo trata-se de uma pesquisa realizada através de uma revisão bibliográfica de literatura de abordagem qualitativa descritiva que constitui um método de buscas para analisar e descrever um determinado conhecimento com o objetivo de obter uma resposta de acordo com os artigos na íntegra, voltados à temática corrente.

Para o levantamento, foi realizada uma apuração com o tema desejado com intuito de fomentar a busca e conhecimento sobre a temática proposta. Foram consultados no banco de dados Descritores em Ciências da Saúde (DeCS) através dos artigos da BIREME, SciELO e Lilacs no período de 2015 a 2019, sendo utilizado os seguintes descritores, acidentes de trabalho, enfermagem, perfurocortante, saúde do trabalhador.

Desta busca resultou um total de 13 referências, sendo compiladas apenas 9 que atendiam ao tema proposto nesta pesquisa, foram excluídos os artigos que não falavam especificamente sobre os acidentes com perfurocortante, sendo utilizados apenas aqueles que mais tratavam sobre $\mathrm{o}$ assunto relacionado à temática $\mathrm{e}$ lidos na íntegra, e analisados quanto às variáveis: ano, título, objetivos e resultados, seguindo seis etapas.

A primeira etapa: levantamento de materiais bibliográficos com o propósito de embasar e nortear o relato a serdesenvolvido, possibilitando enriquecimentoe contribuição da cientificidade na temática apresentada.

A segunda etapa: estabelecimento de critérios para inclusão e exclusão de estudos/ amostragem ou busca na literatura. Os critérios de inclusão definidos para a seleção dos artigos foram: artigos publicados em português, que abordassem os temas sobre saúde do trabalhador, acidentes biológicos na enfermagem, acidentes com perfuro cortantes nos últimos 05 anos.

A terceira etapa: definição das informações a serem extraídas dos estudos selecionados categorização dos estudos.

A quarta etapa: avaliação dos resultados obtidos.

A quinta etapa: discussão dos principais dados coletados.

\section{Resultados e Discussão}

Para os resultados foram encontrados 13 artigos, após analise de inclusão e exclusão, foram selecionados 9 , sendo expostas as publicações conforme o quadro1.

No quadro 1 os resultados evidenciam que os estudos apresentaram uma grande preocupação com a temática perfurocortante, sugerindo uma atenção prioritária no contexto acadêmico, material biológico, repercussões de acidente de trabalho, dificuldade do enfrentamento do enfermeiro ao lidar com acidentes perfurocortantes, atenção ao setor de urgência ao se tratar de uma área de risco, estratégia educativas, sendo essa um dos pilares fundamentais para prevenção e redução de acidentes, as doenças por HIV, um assunto mais discutidos e enaltecidos pelos autores supracitados.

Diante dos objetivos pesquisados, conforme demonstra o quadro 2, a classe de enfermagem vem ganhando destaque. Os artigos tiveram como proposta reforçar o levantamento nas complicações que o acidente perfurocortante pode trazer como um fator que poderá gerar inúmeros problemas tanto no contexto clínico, nas instancias acadêmicas, levando em consideração a exposição da equipe de enfermagem do material biológico, estendendo ao contágio pelo HIV.

Processo de análise foi remetido por (tantos \%) de 3 pesquisadores que trouxeram como contribuição a discussão a esta temática enaltecendo os aspectos de prevenção, o significado do impacto na vida do 
Quadro 1. Demonstrativo dos Títulos e Autores encontrados .

\begin{tabular}{|c|c|}
\hline TÍTULOS DOS ARTIGOS & NOME DOS AUTORES \\
\hline $\begin{array}{l}\text { Acidentes de trabalho no campo da prática dos acadêmicos de enfer- } \\
\text { magem (2015). }\end{array}$ & $\begin{array}{l}\text { Gomes, Suelen Veras; Rodrigues, Clarice Maria de Araujo; Perei- } \\
\text { ra, Érika Almeida Alves; Handem, Priscila de Castro; Passos, Joanir } \\
\text { Pereira. }\end{array}$ \\
\hline $\begin{array}{l}\text { Acidente de trabalho com material biológico: fatores associados ao } \\
\text { abandono do acompanhamento clínico-laboratorial (2019). }\end{array}$ & $\begin{array}{l}\text { Sardeiro, Tatiana Luciano; Souza, Camila Lucas de; Salgado, Thaís } \\
\text { de Arvelos; Galdino Júnior, Hélio; Neves, Zilah Cândida Pereira; Ti- } \\
\text { pple, Anaclara Ferreira Veiga. }\end{array}$ \\
\hline $\begin{array}{l}\text { As dificuldades enfrentadas pelo enfermeiro do trabalho na preven- } \\
\text { ção de acidentes e doenças ocupacionais (2017). }\end{array}$ & $\begin{array}{l}\text { Rafael Braga de Almeida1, Rodrigo Marques da Silva, Iel Marciano } \\
\text { de Moraes Filho. }\end{array}$ \\
\hline $\begin{array}{l}\text { Significados contextuais e o acidente perfurocortante: repercussões } \\
\text { para o cuidado de enfermagem (2018). }\end{array}$ & $\begin{array}{l}\text { Rosa, Lígia Santana; Valadares, Gláucia Valente; Pedreira, Querén- } \\
\text { Hapuque Delaquila Machado; Ribeiro, Laura Regina. }\end{array}$ \\
\hline $\begin{array}{l}\text { Riscos de acidentes com materiais perfurocortantes no setor de ur- } \\
\text { gência de um hospital público (2016). }\end{array}$ & $\begin{array}{l}\text { Silva, Francisca Francineide Andrade da; Farias, Hercilla Nara Con- } \\
\text { fessor Ferreira de; Costa, Romanniny Hévillyn Silva; Souza, Nilba } \\
\text { Lima de; Carvalho, Jovanka Boittencourt Leite de; Silva, Richardson } \\
\text { Augusto Rosendo da. }\end{array}$ \\
\hline $\begin{array}{l}\text { Exposição ocupacional a fluidos biológicos em acidentes com perfu- } \\
\text { rocortantes na equipe de Enfermagem hospitalar (2019). }\end{array}$ & $\begin{array}{l}\text { Aragão, José Aderval; Fontes, Letícia Moreira; Aragão, Iapunira Ca- } \\
\text { tarina Sant'Anna; Aragão, Felipe Matheus Sant'Anna; Reis, Fran- } \\
\text { cisco Prado. }\end{array}$ \\
\hline $\begin{array}{l}\text { Acidente com material biológico sob a ótica dos estudantes de enfer- } \\
\text { magem: reflexões para o ensino (2019). }\end{array}$ & $\begin{array}{l}\text { Cardoso, Najara Queiroz; Ream, Priscilla Santos Ferreira; Souza, } \\
\text { Camila Lucas de; Salgado, Thaís de Arvelos; Galdino Júnior, Hélio; } \\
\text { Tipple, Anaclara Ferreira Veiga. }\end{array}$ \\
\hline $\begin{array}{l}\text { Manuseio e descarte de perfurocortantes por profissionais de enfer- } \\
\text { magem de unidade de terapia intensiva. }\end{array}$ & $\begin{array}{l}\text { Alessandra da Terra Lapa; Pricilla Del Giudice Dias; Thelma Spin- } \\
\text { dola; Jessica Mello da Silva; Paula Raquel dos Santos; Larissa Pe- } \\
\text { reira Costa }\end{array}$ \\
\hline
\end{tabular}

Quadro 2. Objetivos levantados nos artigos.

Descrever as condições de risco para acidente de trabalho na visão dos acadêmicos de enfermagem e discutir as implicações do acidente de trabalho para a saúde dos estudantes.

Analisar a epidemiologia do abandono do acompanhamento clínico e laboratorial entre os trabalhadores de saúde que sofreram acidentes com material biológico.

Analisar as evidências científicas sobre as principais dificuldades que o enfermeiro em Saúde ocupacional enfrenta na prevenção de acidentes e no cuidado a doenças no ambiente organizacional.

Analisar o significado contextual em que ocorre o acidente com equipamento perfurocortante.

Conhecer os fatores de risco relacionados aos acidentes com material perfurocortante presentes no trabalho dos técnicos de enfermagem do setor de atendimento de urgência de um hospital público.

Determinar a ocorrência de exposição ocupacional a fluidos biológicos em acidentes com perfurocortantes na equipe de enfermagem hospitalar.

Identificar atividades de risco para acidentes com material biológico segundo estudantes de enfermagem e o conhecimento das medidas frente ao acidente, descrever frequência e perfil dos acidentes e identificar o atendimento pós exposição.

Identificar os fatores que expõem os trabalhadores de enfermagem de UTI aos acidentes por perfurocortantes durante a sua manipulação e descarte.

Analisar por meio do Diagrama de Ishikawa as causas e soluções da infecção ao HIV adquirida por profissionais de enfermagem no manuseio de materiais perfurocortantes. 
trabalhador e possíveis soluções mediante a infecção pela HIV.

$2 \%$ dos pesquisadores trouxeram também em seus estudos a preocupação com a saúde dos estudantes, principalmente pela falta de experiência ao lidar com o cotidiano hospitalar incluindo o nervosismo, ansiedade, o medo de errar.

Os demais autores buscaram conhecer os fatores de risco, principalmente no setor de urgência, e trouxeram o levantamento da ocorrência que a exposição ocupacional poderia trazer para a equipe.

Daí a importância de discutir e criar estratégias científicas e práticas que venham denotar a melhor assistência de qualidade de vida para a saúde do trabalhador envolvido, e dos acadêmicos que porventura venham trafegar nos cenários hospitalares.

Gráfico 1. Anos de Artigos Publicados.

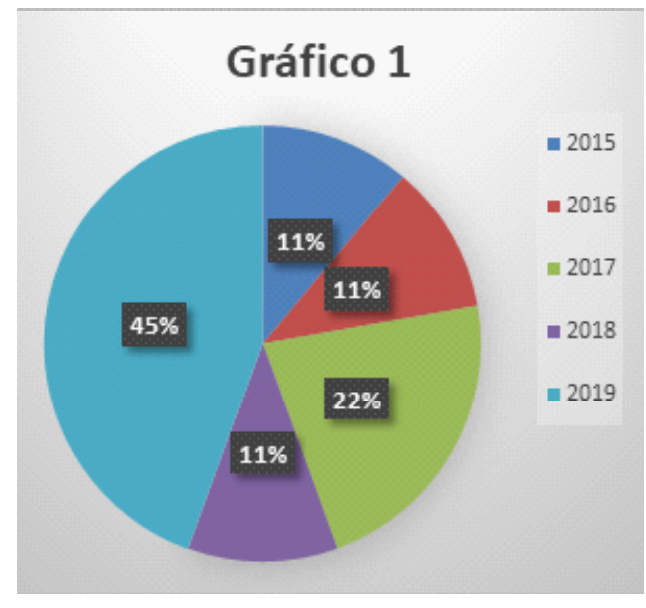

Fonte: Dados dos Autores, 2021

Percebe-se, no gráfico 1, o número relevante de pesquisas em torno de $45 \%$ realizadas no ano de 2019 , o que sugere uma preocupação dos pesquisadores em buscar soluções, principalmente em relação às subnotificações que impedem estratégias assertivas a fim de entender fenômenos relacionados aos acidentes perfurocortantes. O cunho científico demonstra que esta temática ainda necessita ser discutida para uma ação mais prática e eficiente na redução de acidentes laborais nos espaços de saúde.

Em segundo lugar, encontramos $22 \%$ de pesquisas que foram realizadas no ano de 2017, quando os pesquisadores atentaram para a preocupação com as doenças que os acidentes perfurocortantes poderiam acontecer para o trabalhador de saúde, e as barreiras e dificuldades encontradas pelos enfermeiros ao sensibilizar os profissionais quanto à utilização e a normatização dos equipamentos de proteção individual, além da falta de adesão e investimento na área educativa para atender a esta população em questão, tema muito atual nos dias vindouros.

Nos anos de 2015, 2016 e 2018, obtivemos o somatório de $11 \%$, e tornou-se relevante para os autores discutir sobre o cenário do setor de urgência e emergência, que tem as suas complexidades e a necessidade de implantar a cultura de segurança, a fim de melhorar os padrões assistenciais e agilizar o atendimento, sem colocar em risco a equipe. Porém, 2015 os autores vão discutir a questão de subnotificação que foi citada em 2016, só que referente à população acadêmica que necessita, também, de aporte para sua segurança e todas essas instâncias, segundo os autores.

\section{Conclusão}

O estudo evidenciou que tanto os profissionais de enfermagem quanto aos acadêmicos estão expostos aos riscos de acidentes com materiais perfurocortantes, e os profissionais especificamente expostos a altas cargas de trabalho, ambiente hostis, o que vem ocasionando os acidentes laborais, levando a vários danos sendo de origem psíquica, biológica e as contaminações.

É imprescindível a fiscalização do cumprimento das normas de biossegurança para que os acidentes de trabalho não sejam subnotificados, o que pode desencadear injúrias que inviabilizarão o acompanhamento sorológico.

Percebe-se a necessidade de trabalhar na educação continuada através das capacitações, fomentar projetos que enalteçam o investimento na saúde do trabalhador a fim de evitar que estes acidentes ocorram, removendo os fatores para o desencadeamento dos danos, como princípio de um efeito dominó que começa a partir da sobrecarga de trabalho, quando o profissional perde o interesse, caminhando para o desgaste físico, psíquico e emocional, que levam para a falta de atenção e ao descuido, acarretando o descarte inapropriado dos perfurocortantes, levando, por fim, a uma injúria e a infecção pelo HIV, Hepatite B e Hepatite C.

\section{Referências}

1. Lima, MJ. O que é enfermagem / Maria José de Lima. - 2. Ed. - São Paulo: Brasiliense, 1994. ---- (Coleção primeiros passos; 227).

2. Associação Nacional de Enfermagem do Trabalho - ANENT [homepage na internet]. Atribuições do Enfermeiro do Trabalho. [acesso em: maio 2020]. Disponível em: http://www. anent.org.br/atribuicoes/index.htm

3. Carmo TA, Masson VA, Tasso CAS. Assistência de Enfermagem do Trabalho: prevenção de doenças ocupacionais. Rev Cienc Inovação FAM 2016; 3(1):48 Disponível em: acesso: maio. 2020

4. Nightingale F. Notas sobre enfermagem: o que é e o que não é. Tradução de Amália Correa de Carvalho. São Paulo: Cortez; 1989.

5. Medeiros ABA, Enders BC, Lira ALBDC. Teoria Ambientalista de Florence Nightingale: Uma Análise Crítica. Esc. Anna Nery. 2015;19(3):518524

6. Dahlgren G, Whitehead M. Policies and Strategies to Promote Social 
Equity in Health. Stockholm: Institute for Future Studies, 1991.

7. Brasil. Ministério da Saúde. Secretaria de Atenção à Saúde. Secretaria de Vigilância em Saúde. Saúde do trabalhador e da trabalhadora [recurso eletrônico] / Ministério da Saúde, Secretaria de Atenção à Saúde, Secretaria de Vigilância em Saúde, Cadernos de Atenção Básica, n. 41 - Brasília: Ministério da Saúde, 2018.

8. Brasil. Ministério da Saúde. Secretaria de Políticas de Saúde. Departamento de Atenção Básica. Área Técnica de Saúde do Trabalhador Saúde do trabalhador / Ministério da Saúde, Departamento de Atenção Básica, n. 5 - Departamento de Ações Programáticas e Estratégicas, Área Técnica de Saúde do Trabalhador. - Brasília: Ministério da Saúde, 2001.

9. Brasil, Lei $n^{\circ} 8.213$, de 24 de julho de 1991. Dispõe sobre os Planos de Benefícios da Previdência Social e dá outras providências. Diário Oficial da União. Brasília, 25/07/1991. Disponível em: https://www2.camara.leg.br/ legin/fed/lei/1991/lei-8213-24-julho-1991-363650-publicacaooriginal-1-pl. html. Acesso em: 28/03/2020.

10. Bulhões, I. Riscos do trabalho de enfermagem. Rev. bras. enferm. [Internet]. 1994 mar [cited 2021 Jan 21]; 47(1): 84-84. Disponível em: http:// dx.doi.org/10.1590/S0034-71671994000100017. acesso 15 de abril de 2020

11. Silva VEF. O desgaste do trabalhador de enfermagem: relação trabalho de enfermagem e saúde do trabalhador [tese doutorado]. São Paulo: Escola de Enfermagem, Universidade de São Paulo; 1996.

12. Felli VEA, Tronchin DMR. A qualidade de vida no trabalho e a saúde do trabalhador de enfermagem. In: Kurcgant $\mathrm{P}$, coordenadora. Gerenciamento em enfermagem. Rio de Janeiro: Guanabara Koogan; 2010. p. 89-107.

13. Marziale MHP, Rodrigues CMA. Produção científica sobre os acidentes de trabalho com material perfurocortante entre trabalhadores de enfermagem. Revista Latino-Americana de Enfermagem, Ribeirão Preto, v. 10, n. 4, p. 571-577, jul./ago. 2002.

14. Flores TS, Couto PLS, Vilela ABA, Silva JÁ, Pereira SSC, de Souza EC. A síndrome do esgotamento profissional (Burnout) como injúria aos direitos trabalhistas: princípios do dano existencial. Revista Pró-UniverSUS. 2019 Jul./Dez.;10 (2):48-52.

15. Oliveira F. A persistência da noção de ato inseguro e a construção da culpa: os discursos sobre os acidentes de trabalho em uma indústria metalúrgica. Rev. bras. saúde ocup. [Internet]. 2007 june [cited 2020 jun 22] ; 32 ( 115 ): 19-27. http://dx.doi.org/10.1590/S0303-76572007000100003.

16. Heinrich, HW. Industrial accident prevention: a scientific approach . New York: Mac Graw Hill, 1959.

17. Brasil. Ministério do Trabalho e Emprego. NR 32 - Segurança e Saúde no Trabalho em Serviços de Saúde. Portaria GM n ${ }^{\circ} 485$, de 11 de novembro de 2005. Diário Oficial da União, Brasília, DF, 16 nov. 2005. Disponível em: $<$ https://www20.anvisa.gov.br/segurancadopaciente/index. $\mathrm{php} /$ legislacao/item/portaria-n-485-de-11-de-novembro-de-2005 >. Acesso em: 14 abr. 2020.

18. Almeida RB, Silva RM, Moraes-Filho IM. As dificuldades enfrentadas pelo enfermeiro do trabalho na prevenção de acidentes e doenças ocupacionais - revisão de literatura. Rev. Cient. Sena Aires. 2017; 6(1): 5971.

19. Aragão JÁ, Fontes LM, Aragão ICS, Aragão FMS, Reis FP. Exposição ocupacional a fluidos biológicos em acidentes com perfurocortantes na equipe de enfermagem hospitalar. Enferm. foco (Brasília) ; 10(1): 58-64, jan. 2019.

20. Cardoso NQ, Ream PSF, Souza CL, Salgado TA, Galdino Júnior H, Tipple AFV. Acidente com material biológico sob a ótica dos estudantes de Enfermagem: reflexões para o ensin. Enferm. foco (Brasília); 10(3): 2-8, jul. 2019.

21. Gomes SV, Rodrigues CMA, Pereira EAA, Handem PC, Passos JP. Acidentes de trabalho no campo da prática dos acadêmicos de enfermagem. Rev. Pesqui. (Univ. Fed. Estado Rio J., Online) ; 7(4): 3366-3374, out.-dez. 2015 .

22. Lapa AT, Dias PDG, Spindola T, Silva, JM, Santos PR, Costa LP. Manuseio e descarte de perfurocortantes por profissionais de enfermagem de unidade de terapia intensiva. Revista de Pesquisa: Cuidado é Fundamental Online, [S.1.] 2017;9(2):387-392, apr. ISSN 2175-5361.
23. Lima NS, Rodrigues BFL, Ferreira MAM, Santos TD, Rodrigues TDB, Patrício ACFA. Diagrama de Ishikawa: causas e soluções da infecção ao HIV adquirida por profissionais de enfermagem através de materiais perfurocortantes. Rev. pesqui. cuid. fundam. (Online) , 2019 abr.-maio; 11(3):707-712.

24. Rosa LS, Valadares GV, Pedreira QHDM, Ribeiro, LR. Significados contextuais e o acidente perfurocortante: repercussões para o cuidado de enfermagem. Rev. enferm. UERJ, 2018 jan.-dez; 26: e33767.

25. Sardeiro, TL et al . Acidente de trabalho com material biológico: fatores associados ao abandono do acompanhamento clínico-laboratorial. Rev. esc. enferm. USP, São Paulo, 2019 dez; 53, Epub 02: e03516.

26. Silva FFA, Farias HNCF, Costa RHS, Souza NL, Carvalho JBL, Silva RAR. Riscos de acidentes com materiais perfurocortantes no setor de urgência de um hospital público. Rev. Pesqui. 2016 out.-dez; 8(4): 5074 5079 